\title{
STRAIN ENERGY-AND STRESS-BASED APPROACHES REVISITED IN NOTCH FATIGUE OF DUCTILE STEELS
}

\author{
Bruno Atzori", Mauro Ricotta, and Giovanni Meneghetti \\ ${ }^{1}$ Department of Industrial Engineering, University of Padova, 35131 Padova, Italy
}

\begin{abstract}
The constant amplitude, zero-mean stress, axial-fatigue behaviour of plain and bluntly notched AISI $304 \mathrm{~L}$ stainless steel specimens is investigated in terms of strain energy density. Concerning plain material, it was found that at the fatigue knee the plastic strain energy density is 1.49 times higher than the elastic strain energy density. In the authors' opinion, the presence of plasticity at the fatigue knee is responsible for the unsuitableness of classical stress - based approaches to synthesise the fatigue behaviour of this material. On the contrary, the elastic-plastic strain energy density was found an efficient parameter to rationalise in a single scatter band fatigue data of plain and bluntly notched specimens. Based on this result, the classic stress- and the point stress- based approaches were revisited taking into account the presence of plasticity at the fatigue knee, by introducing an equivalent fully elastic material having a linear elastic strain energy density at the fatigue knee equal to that of the actual material. Accordingly, a coefficient of plasticity $\mathrm{K}_{\mathrm{p}}$ was successfully introduced to modify the classical definition of fatigue strength reduction factor, $\mathrm{K}_{\mathrm{f}}$.
\end{abstract}

\section{Introduction}

Design against fatigue is a key aspect for structural designers, in particular when notch effects are present. Usually, the fatigue strength of notched components is assessed starting from the fatigue strength of plain specimens, which is expressed by means of equations relating a damage variable with the number of cycles to failure.

Stress-, strain- or energy-based approaches are available in literature to correlate the fatigue strength of plain materials. Concerning the energy-based methods, some of them has been developed under the hypothesis of linear elastic material [1-4], others require the knowledge of cyclic elastic-plastic material behaviour (see 5-11, as examples).

Referring to AISI 304L stainless steel, the authors showed that neither net-section nor linear elastic peak stresses are able to rationalise in a single scatter curve the fatigue life of bluntly notched specimens. On the contrary, it was successfully synthesised in a single scatter band, by considering the dissipated heat energy density per cycle (the $\mathrm{Q}$ parameter) as fatigue damage indicator [12].

In this paper, first the elastic-plastic SED was successfully confirmed as an effective index able to rationalise fatigue data, obtained by carrying out fully reversed fatigue test on plain and bluntly notched specimens made from hot rolled AISI 304L stainless steel sheet. After that, with the aim to provide designers with a relative simple tool to make linear elastic calculations also in the presence of plasticity at the fatigue knee, the classical stress- and the point stressbased approaches were revisited, in terms of energybased concept. As a result, the use of a modified fatigue notch factor allowed evaluating the fatigue strength of notched specimens in very good agreement with the experimental data.

\section{Theoretical background}

In this paper the elastic-plastic Strain Energy Density is assumed the damage variable able to correlate the fatigue strength of plain and notched components. The underlying concept is that two components have the same fatigue life when they have the same level of elastic-plastic SED. Usually at the fatigue knee, the plain material behaviour is supposed to be elastic and consequently the relevant strain energy is equal to the elastic strain energy density, $\mathrm{W}_{\mathrm{LE}}$

$$
W_{L E}\left(\sigma_{0}\right)=\frac{\sigma_{0}^{2}}{2 \cdot E}
$$

being $\sigma_{0}$ the material fatigue limit and $\mathrm{E}$ its elastic modulus.

Nevertheless, when at the fatigue knee plasticity can not be neglected, the relevant elastic-plastic SED can be calculated according to Eq. 2:

$$
W_{C C}\left(\sigma_{0}\right)=W_{C C}^{E}\left(\sigma_{0}\right)+W_{C C}^{P}\left(\sigma_{0}\right)
$$


where $W_{C C}^{E}\left(\sigma_{0}\right)$ and $W_{C C}^{P}\left(\sigma_{0}\right)$ is the elastic and the plastic component of $W_{C C}\left(\sigma_{0}\right)$, respectively. The material cyclic behaviour can be described by the Ramberg-Osgood law, according to which the strain is the sum of its elastic, $\varepsilon^{\mathrm{E}}$, and its plastic component, $\varepsilon^{\mathrm{P}}$, as follows:

$$
\varepsilon=\varepsilon^{E}+\varepsilon^{P}=\frac{\sigma}{E}+\left(\frac{\sigma}{K^{\prime}}\right)^{\frac{1}{n^{\prime}}}
$$

where $K^{\prime}$ is the cyclic strength coefficient and $n^{\prime}$ the cyclic hardening exponent. Therefore, it can be derived that:

$$
W_{C C}^{E}\left(\sigma_{0}\right)=\frac{1}{2} \sigma_{0} \cdot \varepsilon_{0}^{E}=\frac{\sigma_{0}^{2}}{2 E}
$$

$$
W_{C C}^{P}\left(\sigma_{0}\right)=\frac{1}{1+n^{\prime}} \cdot \sigma_{0} \cdot \varepsilon_{0}^{P}=\frac{1}{1+n^{\prime}} \cdot \sigma_{0} \cdot\left(\frac{\sigma_{0}}{K^{\prime}}\right)^{\frac{1}{n^{\prime}}}
$$

$\varepsilon_{0}^{E}$ and $\varepsilon_{0}^{P}$ being the elastic and the plastic component of the strain at the fatigue knee, respectively. Therefore, the high cycle fatigue strength of bluntly notched components can be performed by comparing the elasticplastic SED, evaluated at the notch root, to the elasticplastic SED of plain material. Since elastic-plastic SED evaluation on components requires non-linear finite element analyses and often structural designers are more familiar with stress- than energy-based approaches, in this paper the nominal stress- and the point stress- based approaches are revised to take into account the presence of plasticity at the fatigue knee, on the basis of energy considerations.

The nominal stress approach is based on the assumption that a notched component reaches the fatigue knee when an effective stress acting at the notch tip, $\sigma_{\text {eff, is equal to }}$ the fatigue limit of plain material. Usually, $\sigma_{\text {eff }}$ is evaluated by starting from the evaluation of a nominal stress $\sigma_{\text {nom }}$ properly increased by using the fatigue notch factor $\mathrm{K}_{\mathrm{f}}[13,14]$. In general, $\mathrm{K}_{\mathrm{f}}$ is an experimental parameter defined as:

$$
K_{f}=\frac{\text { fatigue limit of unnotched specimen }}{\text { fatigue limit of notched specimen }}
$$

It is well known that when the $\mathrm{K}_{\mathrm{f}}$ value is not available, it can be estimated by starting from the theoretical stress concentration factor $\mathrm{K}_{\mathrm{t}}$ and the notch sensitivity index $\mathrm{q}$, according to Peterson [13]:

$$
q=\frac{K_{f}-1}{K_{t}-1}
$$

The values of $\mathrm{q}$ vary from $\mathrm{q}=0$ for no notch effect $\left(\mathrm{K}_{\mathrm{f}}=0\right)$ to $\mathrm{q}=1$ for the full theoretical effect $\left(\mathrm{K}_{\mathrm{f}}=\mathrm{K}_{\mathrm{t}}\right)$.
In the classical approach, the behaviour of plain material is supposed to be fully elastic, at least at the fatigue limit. In order to overcome this limitation, in this paper an equivalent fatigue limit $\sigma_{0, \text { eq }}$ is introduced such that the SED experimentally measured at the fatigue knee for plain material is equal to that of an equivalent fully elastic plain material, following the original idea proposed by Glinka $[15,16]$, regarding notched components:

$W_{L E}\left(\sigma_{0, e q}\right)=W_{C C}\left(\sigma_{0}\right)=W_{C C}^{E}\left(\sigma_{0}\right)+W_{C C}^{P}\left(\sigma_{0}\right)$

where $W_{L E}\left(\sigma_{0, e q}\right)=\frac{\sigma_{0, e q}^{2}}{2 \cdot E}$.

Let us to define a coefficient of plasticity $\mathrm{K}_{\mathrm{p}}$, as follows:

$K_{p}=\frac{\sigma_{0, e q}}{\sigma_{0}}=\sqrt{\frac{W_{L E}\left(\sigma_{0, e q}\right)}{W_{S C C}^{E}\left(\sigma_{0}\right)}}=\sqrt{1+\frac{2}{1+n^{\prime}} \cdot R_{p}}$

being $\mathrm{R}_{\mathrm{p}}=\varepsilon_{0}^{P} / \varepsilon_{0}^{E}$ the plasticity ratio evaluated at the fatigue limit. The $K_{p}$ coefficient versus $R_{p}$ of plain material is plotted in Fig. 1 for different values of $n$ '. Other approaches are available in literature to correlate elastic-plastic to linear elastic analyses. Of these, Neuber's rule is the most widely used and the relevant $\mathrm{K}_{\mathrm{p}}$ versus $\mathrm{R}_{\mathrm{p}}$ trend is plotted in the same figure, according to Eq. $8 \mathrm{~b}$

$$
K_{p}^{N}=\sqrt{1+R_{p}}
$$

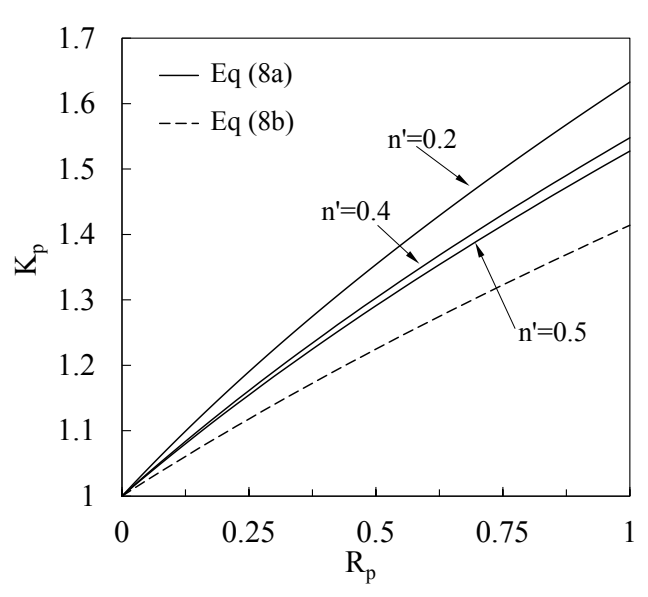

Fig. 1. $K_{p}$ versus $R_{p}$ trend for different values of cyclic hardening exponent.

Therefore, the classical approach can be extended to materials characterised by plasticity at the fatigue knee, by imposing that a notched component reaches the fatigue knee when the effective stress $\sigma_{\text {eff }}$ is equal to $\sigma_{0, \text { eq }}$. In the case of full theoretical effect $q=1$ (i.e. $\mathrm{K}_{\mathrm{f}}=\mathrm{K}_{\mathrm{t}}$ ) and by using the net-section stress as nominal stress, it follows:

$$
\sigma_{e f f}=\sigma_{0, e q} \Rightarrow K_{t n} \cdot \sigma_{0, n e t}=K_{p} \cdot \sigma_{0}
$$


where $\sigma_{0, \text { net }}$ is the nominal stress to be applied to the notched component to reach the fatigue knee. Therefore, a new strength reduction factor can be defined which takes into account for the plasticity of plain material at the fatigue knee:

$$
K_{f n, p}=\frac{K_{t n}}{K_{p}}
$$

Eq. 10 being valid when $\mathrm{K}_{\mathrm{tn}}>\mathrm{K}_{\mathrm{p}}$. On the contrary, $\mathrm{K}_{\mathrm{fn}, \mathrm{p}}=1$ when $\mathrm{K}_{\mathrm{p}}<\mathrm{K}_{\mathrm{tn}}$, since in this case one can suppose that the fatigue knee of notched component is equal to that of plain material. When a partial theoretical effect is considered (i.e $0<\mathrm{q}<1$ ):

$$
K_{f n, p}=\frac{1+q \cdot\left(K_{t n}-1\right)}{K_{p}}
$$

Once defined the fatigue knee of notched component, the S-N curve can be completely defined, assuming that in the low cycle fatigue regime the notch effect vanishes, thanks to the diffuse plasticity, that can completely involve the net-section. Usually, in the classical nominal stress approach the stress-life curve is defined for a number of cycles to failure starting from 1000 cycles (e. $\mathrm{g}$ [17]). In view of this, it is assumed that the fatigue strength of notched component is equal to that of the plain material evaluated at $\mathrm{N}=1000$ cycles.

In the '90s, different approaches were proposed to evaluate the fatigue strength of cracked or severely notched components, based on Linear Elastic Fracture Mechanics concepts. The underlying idea was the possibility to evaluate the fatigue limit of components weakened by sharp notches, by means of a linear elastic finite element analysis and comparing the stress value acting at a given distance (or averaged on a suitable distance, area or volume) to the fatigue limit of plain material $[18,19]$. Since this approach is based on the linear elastic analysis of the stress state of notched component, it can be adopted as long as the plain material behaviour is elastic. In order to overcome this limitation, in this paper the same procedure adopted in the case of nominal stress-based method will be adopted to revise the point stress approach. Therefore, at the fatigue knee we have:

$$
\sigma_{p o \text { int }}=\sigma_{0, e q} \Rightarrow K_{t n, p o \text { int }} \cdot \sigma_{0, \text { net }}=K_{p} \cdot \sigma_{0}
$$

or alternatively stated:

$$
\frac{\sigma_{0}}{\sigma_{0, \text { net }}}=\frac{K_{t n, \text { point }}}{K_{p}}
$$

where $\sigma_{\text {point }}$ is the stress acting at a given distance $\mathrm{x}_{0}$ from the notch tip, calculated according to [19], as follows:

$$
x_{0}=\frac{a_{0}}{2}=\frac{1}{2 \pi}\left(\frac{\Delta K_{t h}}{\Delta \sigma_{0}}\right)^{2}
$$

where $\mathrm{a}_{0}$ is the El Haddad et al. [20] material parameter length and $\Delta \mathrm{K}_{\mathrm{th}}$ the threshold range value of the mode I stress intensity factor.

The stress- [21,22] as well as the strain- [23] point approach has been extended to estimate the S-N curve from low to high cycle fatigue regime. The more simple and diffused approach is to assume $\mathrm{x}_{0}$ as a constant and to define fatigue design curves on the basis of a statistical analysis of a significant number of experimental results. In the authors' knowledge, in literature are not available point stress-based approaches developed to evaluate the point-stress design fatigue curve by starting from the fatigue life curve of plain material. In this paper, it is proposed to extend to local approaches, the methodology usually adopted in the case of ductile materials. Therefore, it is assumed that for a fatigue life equal to 1000 cycles, the fatigue strength of notched specimens is equal to that of a plain specimen at the same number of cycle. In fact, the fatigue strength of notched component is driven by the net-stress amplitude, since the notch-effect can be assumed ineffective due to the presence of diffused plasticity. Accordingly, the relevant point stress value can be evaluated simply multiplying the fatigue strength of plain specimen evaluated for $\mathrm{N}=1000$ cycles by $\mathrm{K}_{\text {tn,point }}$.

\section{Material and specimen's geometry}

Constant amplitude, fully-reversed, stress-and strain controlled fatigue tests were carried out on plain specimens, machined from 6-mm-thick, hot rolled AISI 304L stainless steel plate. The mechanical properties of tested material are listed in Table 1 , where $R_{s}$ and $R_{m}$ is the static and the proof strength, respectively. Details of specimens' geometry and test conditions are reported in [12]. The notched specimens were characterised by a 3D stress concentration factor referred to the net section, $\mathrm{K}_{\mathrm{tn}}$, equal to $2.25,3.00$ and 3.70 , for $r_{n}=8 \mathrm{~mm}, 5 \mathrm{~mm}$ and 3 $\mathrm{mm}$, respectively.

Fig. 2a reports all fatigue data referred to plain specimens along with the mean stress-life curve, the 10$90 \%$ survival probability curves, the inverse slope $\mathrm{k}$ and the scatter index $\mathrm{T}_{\sigma}$ defined as $\sigma_{\mathrm{a}, 10 \%} / \sigma_{\mathrm{a}, 90 \%}$. Finally, the constant amplitude material fatigue limit $\sigma_{0}=225 \mathrm{MPa}$, evaluated by means of a stair case procedure at 10 million cycles, is reported.

The Ramberg-Osgood law was adopted to define the material cyclic stress-strain curve. Accordingly, K' and n' were calculated by fitting the experimental data shown in Fig. $2 b$, obtained by carrying out the strain controlled fatigue tests [24].

Having E, $\mathrm{K}^{\prime}$ and $n^{\prime}$, according to Eq. (3), the elastic $\varepsilon^{\mathrm{E}}$ and plastic $\varepsilon^{\mathrm{P}}$ component of strain at the fatigue knee resulted equal to $1.16 \cdot 10^{-3}$ and $1.24 \cdot 10^{-3}$, respectively. Therefore from Eq. $4 \mathrm{a}$ and $4 \mathrm{~b}$ one can calculate $W_{C C}^{E}\left(\sigma_{0}\right)=0.130 \mathrm{MJ} / \mathrm{m}^{3}$ and $W_{C C}^{P}\left(\sigma_{0}\right)=0.194 \mathrm{MJ} / \mathrm{m}^{3}$. Finally, Eq. 8 a gives $\mathrm{K}_{\mathrm{p}}=1.58$. It is worth nothing that, at 
the fatigue knee, $W_{C C}^{P}\left(\sigma_{0}\right)$ is 1.49 times higher than $W_{C C}^{E}\left(\sigma_{0}\right)$, showing that the plasticity plays a significant role on the fatigue behaviour of AISI 304L stainless steel. The fatigue data relevant to the notched specimens are shown in Fig. 3a, 3b and 3c in terms of net stress amplitude $\sigma_{\mathrm{a} \text {,net, }}$ together with the reference fatigue strength evaluated at $\mathrm{N}_{0}=160000$ cycles and the experimental fatigue notch factor $\mathrm{K}_{\mathrm{fn}, \text { exp }}$. It was found $\sigma_{0}=186.4,114.5$ and $121.4 \mathrm{MPa}$, for $\mathrm{r}_{\mathrm{n}}=8 \mathrm{~mm}, 5 \mathrm{~mm}$ and $3 \mathrm{~mm}$, respectively, i.e $\mathrm{K}_{\text {fn,sper }}=1.21,1.97$ and 1.85, that are significantly lower than the relevant $\mathrm{K}_{\mathrm{tn}}$ value. Values of $\mathrm{K}_{\mathrm{fn}, \text { sper }}$ are listed in Table 2.
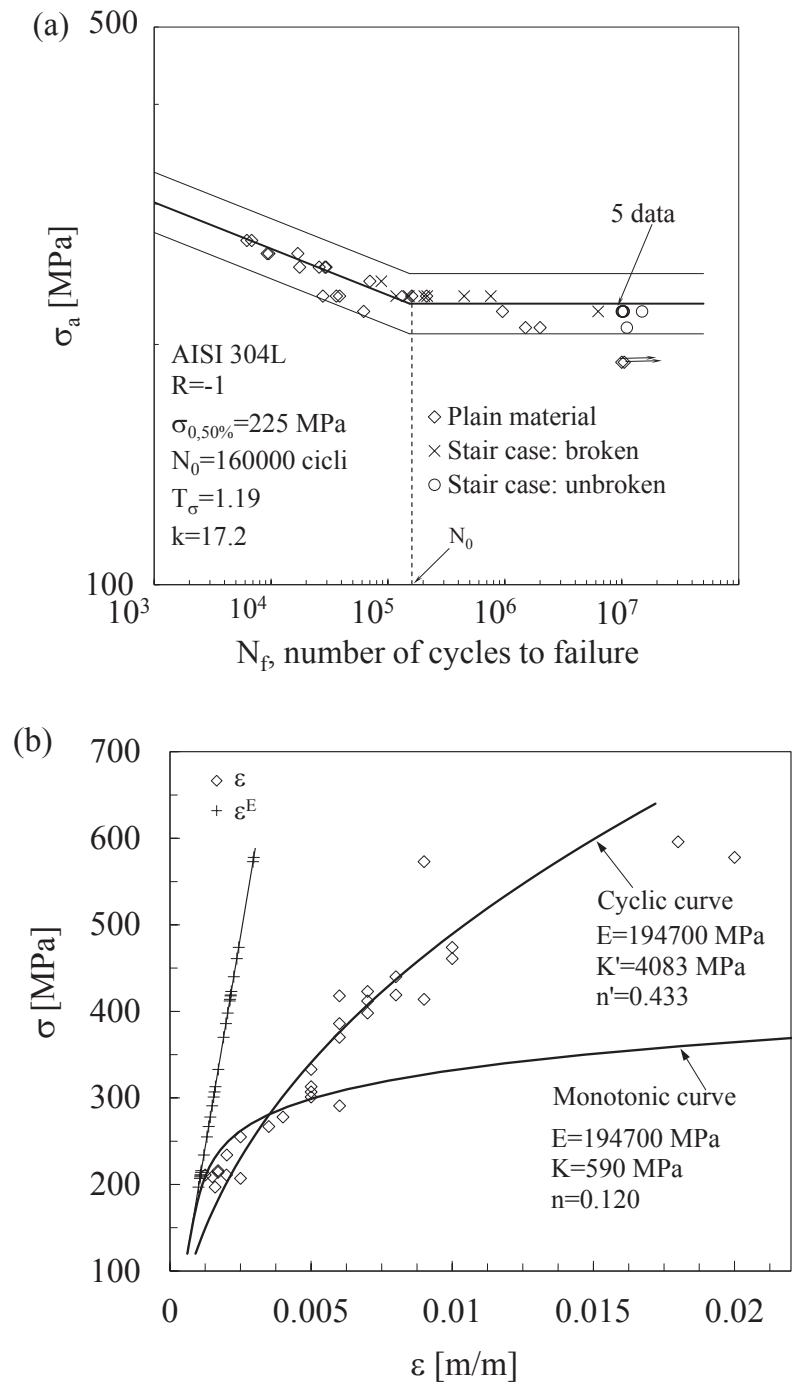

Fig. 2. Stress-life (a) and cyclic stress-strain curve of AISI 304L (b).

Table 1. Mechanical properties of AISI 304L stainless steel.

\begin{tabular}{|c|c|c|c|c|c|}
\hline $\begin{array}{c}\mathrm{E} \\
{[\mathrm{MPa}]}\end{array}$ & $\begin{array}{c}\mathrm{R}_{\mathrm{s}} \\
{[\mathrm{MPa}]}\end{array}$ & $\begin{array}{c}\mathrm{R}_{\mathrm{m}} \\
{[\mathrm{MPa}]}\end{array}$ & $\begin{array}{c}\mathrm{K}^{\prime} \\
{[\mathrm{MPa}]}\end{array}$ & $\mathrm{n}^{\prime}$ & $\begin{array}{c}\sigma_{0} \\
{[\mathrm{MPa}]}\end{array}$ \\
\hline 194700 & 327 & 690 & 4083 & 0.433 & 225 \\
\hline
\end{tabular}

Table 2. Comparison between the experimental and the calculated values of $\mathrm{K}_{\mathrm{fn}}$, taking into account plasticity of plain material.

\begin{tabular}{|c|c|c|c|c|c|}
\hline $\begin{array}{c}\mathrm{r}_{\mathrm{n}} \\
{[\mathrm{mm}]}\end{array}$ & $\mathrm{K}_{\text {fn,exp }}$ & $\mathrm{q}$ & $\mathrm{K}_{\mathrm{tn}}$ & $\mathrm{K}_{\mathrm{fn}, \mathrm{p}}{ }^{*}$ & $\mathrm{~K}_{\mathrm{fn}, \mathrm{p}}{ }^{* *}$ \\
\hline 3 & 1.85 & 0.94 & 3.70 & 2.34 & 2.25 \\
\hline 5 & 1.97 & 0.97 & 3.00 & 1.90 & 1.86 \\
\hline 8 & 1.21 & 0.98 & 2.25 & 1.42 & 1.41 \\
\hline
\end{tabular}

*Eq. $10 ; * *$ Eq. 11
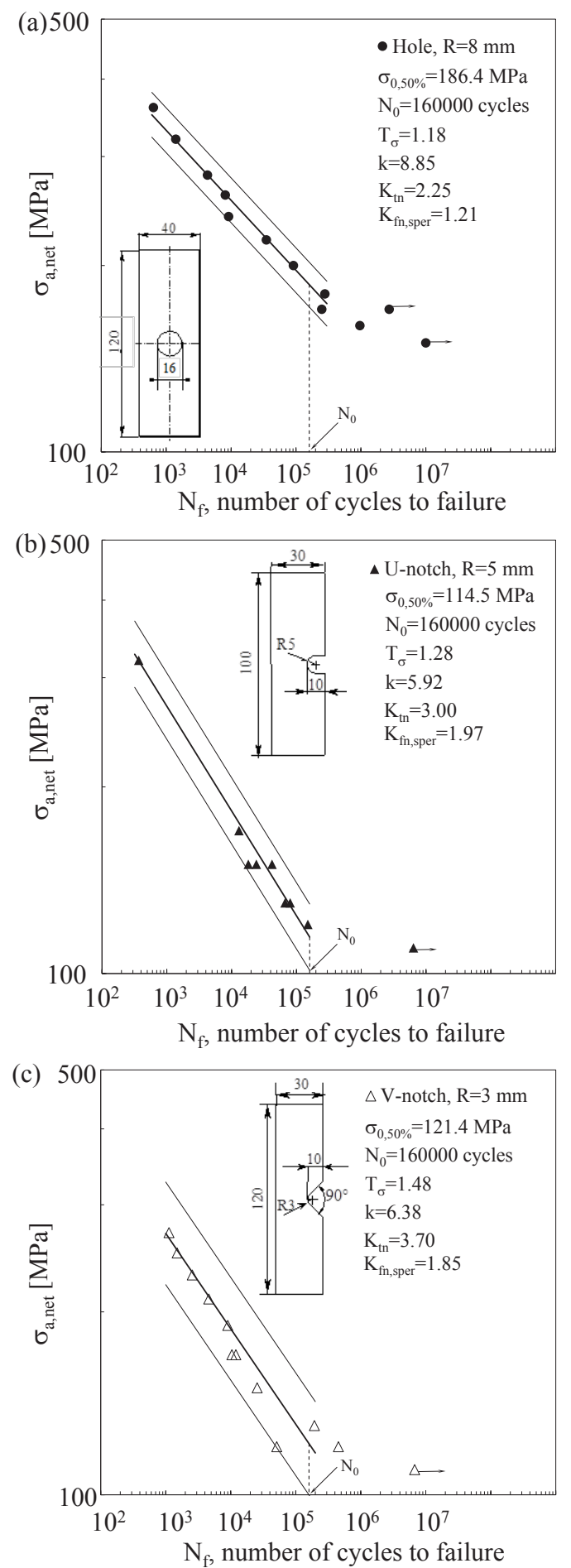

Fig. 3. Stress-life curves of $r_{n}=8 \mathrm{~mm}(\mathrm{a}), r_{n}=5 \mathrm{~mm}$ (b) and $r_{n}=3$ $\mathrm{mm}(\mathrm{c})$ notched specimens.

\section{Fatigue data synthesized in terms of elastic-plastic SED and modified}




\section{nominal stress- and point stress- approaches}

Concerning the plain material, the elastic-plastic SED can be easily calculated from Eqs 4 , by substituting $\sigma_{0}$ with the experimentally applied stress amplitude $\sigma_{\mathrm{a}}$. On the contrary, for notched specimens, 2D plane-strain finite element analyses were performed by using the 8node PLANE183 element of Ansys ${ }^{\circledR}$ commercial software, by using an element size at the notch tip equal to $2 \cdot 10^{-2} \mathrm{~mm}$. The cyclic curve shown in Fig. $2 \mathrm{~b}$ was implemented, along with Von Mises plasticity rule and isotropic hardening behaviour. Fig. 4 shows the fatigue data reanalysed in terms of $\mathrm{W}_{\mathrm{cc}}$, which was evaluated at the notch tip in the case of notched specimens. One can see that at the fatigue knee data relevant to plain and notched specimens can be rationalised with a higher level of accuracy by using $\mathrm{W}_{\mathrm{cc}}$, rather than $\sigma_{\mathrm{a} \text {,net. }}$.

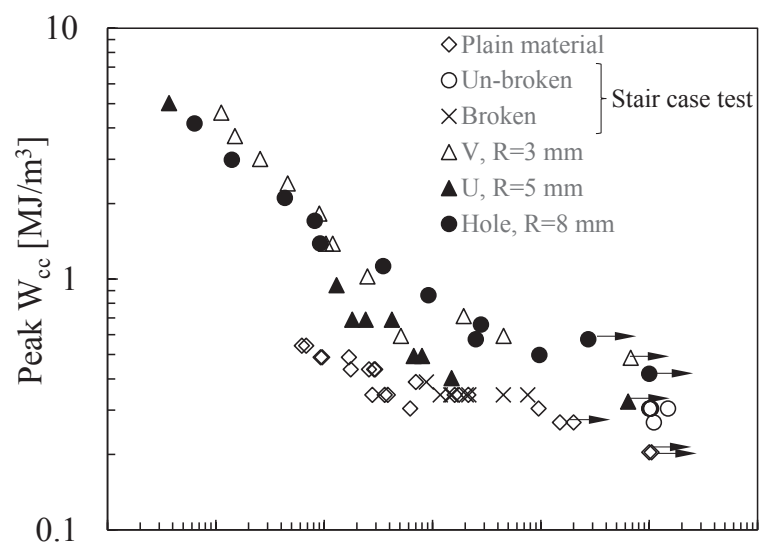

1.E +02 1.E+03 1.E+04 1.E+05 1.E+06 1.E+07 1.E+08 $\mathrm{N}_{\mathrm{f}}$, number of cycles to failure

Fig. 4. Fatigue data reanalysed in terms of peak elastic-plastic Strain Energy Density.

Concerning the material analysed in this paper, the values of $\mathrm{K}_{\mathrm{fn}}$ calculated according to [13] were found equal to $2.17,2.90$ and 3.55 , for $r_{n}=8,5$ and $3 \mathrm{~mm}$, respectively, and they are summarised in Table 2 . The $\mathrm{K}_{\mathrm{fn}, \mathrm{p}}$ values evaluated according to Eq. 10 and 11 are listed in the two last columns of this table. Moreover, as it can be expected considering the notch radii analysed in this paper, negligible differences were found comparing the $\mathrm{K}_{\mathrm{fn}, \mathrm{p}}$ values calculated considering partial- and fulltheoretical notch effect. Figure 5a-c shows the fatigue curves relevant to $r_{n}=3,5$ and $8 \mathrm{~mm}$, respectively, obtained by using the revised stress approach, compared to that calculated according to Peterson [13], here named as "classical approach". Once evaluated the fatigue strength at $\mathrm{N}_{0}=160000$ cycles, the fatigue strength at 1000 cycles was assumed equal to that of a plain specimen at the same number of cycles. Therefore, considering the S-N curve shown in Fig. 1a, it can be calculated equal to $301.4 \mathrm{MPa}$. Fig. 5 shows that a satisfactory agreement with the experimental data can be achieved by using the proposed modified stress-based approach.
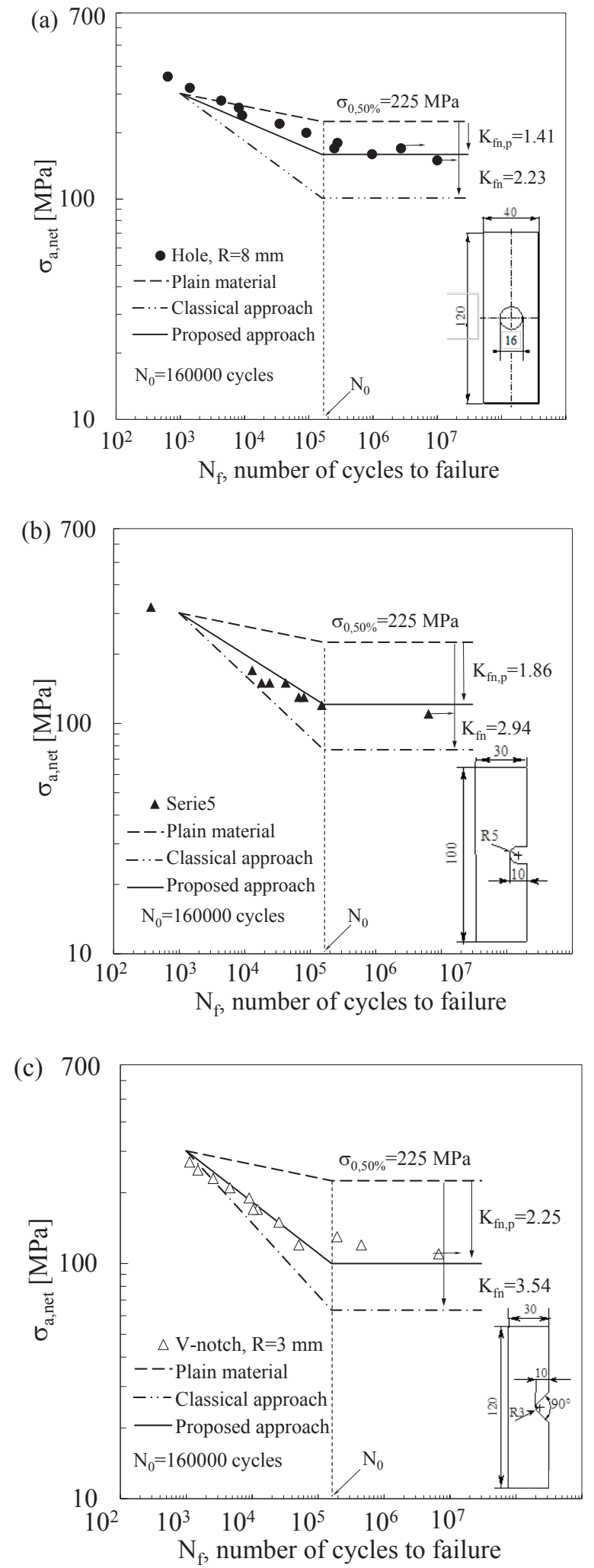

Fig. 5. Fatigue data reanalysed in terms of net-stress amplitude compared to the classical approach (Eq. 5) and the proposed approach (Eq. 10), for $r_{n}=8 \mathrm{~mm}(a), r_{n}=5 \mathrm{~mm}$ (b) and $r_{n}=3 \mathrm{~mm}$ (c).

The application of point stress method requires the evaluation of the distance $\mathrm{x}_{0}$ [19]. Having $\Delta \mathrm{K}_{\mathrm{th}}=8.69$ $M P a \cdot \sqrt{m}$ [25], on can calculate $\mathrm{x}_{0}=0.06 \mathrm{~mm}$, from Eq. 14. Figure 6 shows the experimental results reanalysed 
in terms of point stress $\sigma$ point. It is worth noting that the fatigue knee of notched specimens is significantly different from $\sigma_{0}$, while it is in very good agreement with $\sigma_{0, \text { eq }}$ value.
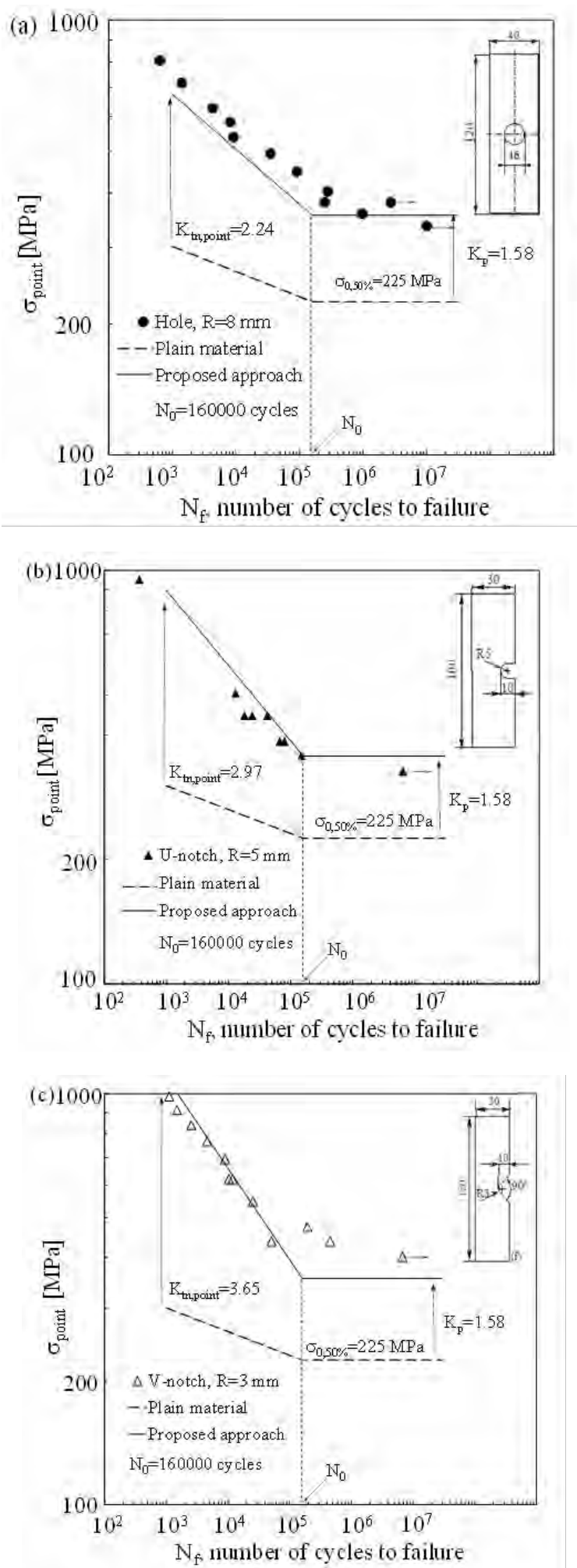

Fig. 6. Fatigue curves evaluated according to the proposed approach $(\mathrm{Eq}$. 13) compared to the experimental data, reanalysed in terms of point-stress, for $r_{n}=8 \mathrm{~mm}(\mathrm{a}), r_{n}=5 \mathrm{~mm}$ (b) and $\mathrm{r}_{\mathrm{n}}=3 \mathrm{~mm}$ (c).
Finally, according to the theoretical background proposed above, the stress point-life curves were completely defined by evaluating the fatigue strength of notched component at $\mathrm{N}=1000$ cycles, multiplying the fatigue strength of plain material evaluated at 1000 cycles $\left(\sigma_{\mathrm{a}}=301.4 \mathrm{MPa}\right)$ by $\mathrm{K}_{\text {tn,point }}$ The results are shown in Figure 6 and it can be noticed a very good agreement with the experimental data.

The proposed methodology was compared to the usual approach of defining a fatigue design scatter band, obtained by a statistical analysis of the experimental results reanalysed in terms of point stress, $\sigma_{\text {point }}$. Figure 7 shows the experimental results of Figure 3 reanalysed in terms of $\sigma_{\text {point }}$, the relevant mean curve, evaluated by assuming a log-normal distribution of the number of cycles to failure and the $10 \%-90 \%$ survival probability scatter band. It was found a reference fatigue strength evaluated at $\mathrm{N}_{0}=160000$ cycles equal to $\sigma_{0 \text {,point }}=337.8$ $\mathrm{MPa}$, that is close to that evaluated by starting from the fatigue limit of plain material, corrected by means of the $\mathrm{K}_{\mathrm{p}}$ coefficient $\left(\sigma_{0, \text { point }} \quad=225 \cdot 1.58=355.5 \mathrm{MPa}\right)$. Moreover, one can see that the fatigue curves relevant the notched geometries fall in the experimental scatter band.

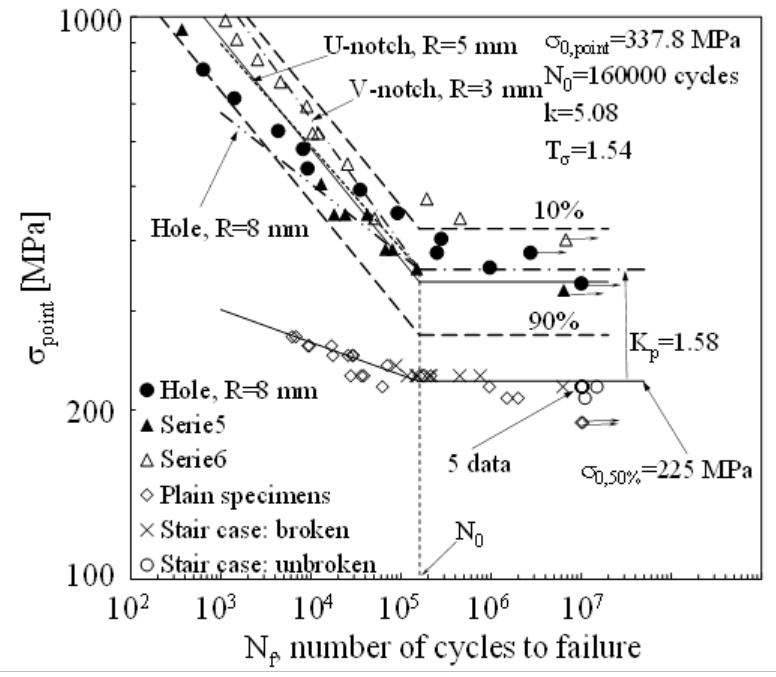

Fig. 7. Fatigue curves evaluated according to the proposed approach (Eq. 13) compared to the experimental scatter band defined by the statistical analysis of fatigue data reanalysed in terms of stress-point.

\section{Conclusions}

In this paper the elastic-plastic Strain Energy Density (SED) was adopted as fatigue index to successfully correlate fatigue data relevant to bluntly notched specimens and plain material made from ductile steels, characterised by the presence of plasticity at the fatigue knee. In general, in the case of notched components, the elastic-plastic SED requires non-linear finite element analyses. On the contrary, the elastic-plastic SED of plain material can be easily evaluated analytically. With the aim to provide structural engineers with a relative simple tool to make linear elastic calculations in the 
presence of notches, the classical nominal stress approach and the point stress method were revisited, on the basis of elastic-plastic SED considerations, saving the advantage of carrying out linear elastic calculations in the presence of notches. In view of this, a $\mathrm{K}_{\mathrm{p}}$ parameter to account for plasticity at the fatigue knee was defined, on the basis of an equivalent fatigue limit, which assures that the elastic-plastic SED evaluated at the fatigue knee is maintained. Once defined the $\mathrm{K}_{\mathrm{p}}$ parameter, the classical stress approach, based on the nominal stress concept, and the point stress method were modified. Finally, the proposed methodology was successfully applied to evaluate the fatigue curve of 6mm-thick, hot-rolled AISI 304 L stainless specimens, weakened by blunt notches, having radius equal to 8,5 and $3 \mathrm{~mm}$, starting from the fatigue curve of plain material.

\section{References}

1. G.C. Sih GC, Int J Fracture, 10, 305-321, (1974).

2. P. Lazzarin, R. Zambardi, Int. J. Fracture, 112, 275298, (2001).

3. Z. Yosibash, O. Adan, R. Schneck, H. Atlas H, Int J Fracture 122, 47-64 (2003).

4. P. Lazzarin, F. Berto, Int J Fracture, 135, 161-185 (2005).

5. C.E. Feltner, J.D. Morrow. Trans ASME Ser D J Basic Eng, 83, 15-22, (1961).

6. J.D. Morrow, International Friction, Damping and Cyclic plasticity, ASTM STP 378, 45-84, American Society for Testing and Materials, Philadelphia, PA (1965).

7. G.R. Halford, J Mater, 19, 3-18, (1966).

8. J. H. Kuang, Y:C. Chen, Eng Fract Mech, 53, 57180 (1996).

9. F. Ellyin, Fatigue damage, crack growth and life prediction. Chapman\&Hall, (1997).

10. R.P. Skelton, T. Vilhelmsen, G:A.Webster, Int J Fatigue, 20, 641-49, (1998)

11. N.W. Klingbeil. Int J Fatigue, 25, 117-128, (2003).

12. G. Meneghetti, M. Ricotta, B. Atzori, Fatigue Fract Eng Mater Struct, 36,1306-1322, (2013).

13. R.E. Peterson, Notch sensitivity. In: Sines G, Waisman JL, editors. Metal fatigue. New York: MacGraw-Hill;. p. 293-306, (1959).

14. M. Ciavarella, G. Meneghetti, Int J Fatigue, 26, 289298, (2004).

15. K. Molski, G. Glinka, Mater Sci Eng, 50, 93-100 (1981)

16. G. Glinka, Eng Fract Mech, 22, $485-508$ (1985).

17. N.E. Dowling, Mechanical behaviour of materials, Pearson Prentice Hall, (2013).

18. K. Tanaka, Int J of Fracture, 22, R39-R46, (1983).

19. D. Taylor, Int J Fatigue, 21, 413-420 (1999)
20. M.H. El Haddad, T.H. Topper, K. N Smith, J of Eng Mater Tech (ASME Trans.) 101, 42-45 (1979).

21. M. Ciavarella, F. Monno, Int J Fatigue, 25, 18261837 (2006).

22. L. Susmel, D. Taylor D, Fatigue Fract Eng Mater Struct, 30, 567-581 (2007).

23. S. Bentachfine, G. Pluvinage, J. Gilgert, Z. Azari, D. Bouam, Int J Fatigue, 21, 421-430 (1999).

24. G. Meneghetti, M. Ricotta, Eng Fract Mech, 81, 2$17,(2012)$.

25. G. Meneghetti, M. Ricotta, D. Rigon, Proceedings of International Fatigue Conference, Cambridge, UK, 3-5 July 2017. 